\title{
Schlich Memorial Fund Award Winner
}

\section{TORONTO}

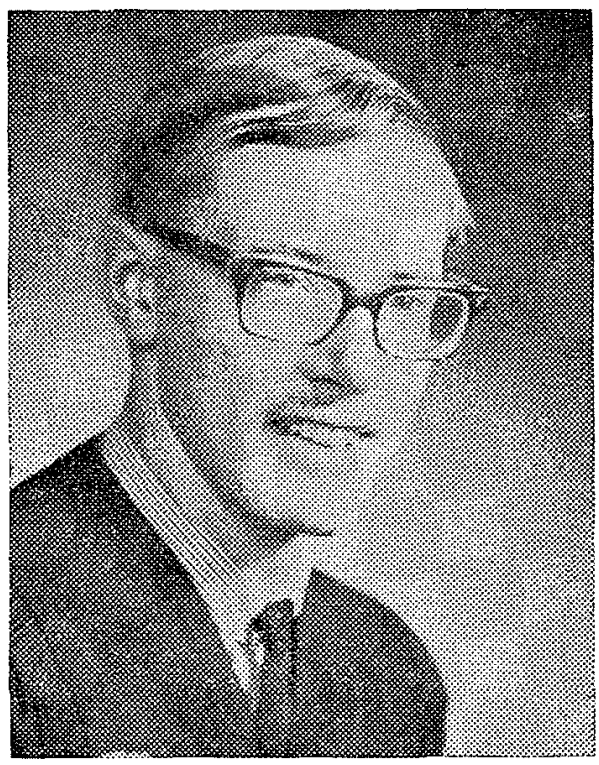

Hans Robert Zuuring, the 1966 winner of the Schlich Memorial Fund Award at the University of Toronto, is the son of Mr. and Mrs. John Zuuring of Toronto. Mr. Zuuring is 23 years of age, and is a graduate of Lorne Park Collegiate Institute.

Mr. Zuuring has been given this Award on the basis of his high standing in the subject of Silviculture during his two final undergraduate years. In addition to maintaining a good academic record, he was editor of the undergraduate publication, The Annual Ring, in the 1965-66 session.

On graduation, Mr. Zuuring will be working for the Federal Department of Forestry in Ottawa. 